\title{
3D Fully Developed Laminar Mixed Convection in Horizontal Concentric Annuli with the Presence of Porous Blocks
}

\author{
Y. Ould-Amer
}

\begin{abstract}
This paper reports the results of a numerical investigation to examine the potential of a four porous blocks inserted specifically for augmenting heat transfer from the inner heated wall of concentric horizontal annuli. Results are presented for a range of the values of the Grashof number, for two value of the Darcy number and for three value of the Prandtl number. Results are presented in the form of contours plots of the streamlines and for the temperature isotherms, and in terms of the overall heat transfer coefficients and friction factor. The average Nusselt number $\left(N u_{b}\right)$ increases significantly with an increase of the Grashof number and the Prandtl number $(P r)$. For pure forced convection, $\mathrm{Nu}_{\mathrm{b}}$ is independent of $\mathrm{Pr}$. With the use of the four porous blocks, the friction factor is consequently increased compared with the situation without porous blocks. The decrease of the Darcy number leads to an increase of the friction factor. If the fully fluid case is taken as a reference, the use of porous blocks is justified only when the ratio of the average Nusselt number to the friction factor is enhanced. At $D a=10^{-3}$, the enhancement occurs for all value of $\mathrm{Pr}$, however, at $D a=10^{-4}$ the improvement is noticeable only for $P r=10$ and 5 after a certain threshold value of Grashof number is exceed.
\end{abstract}

Index Terms-Annuli, concentric, mixed convection, porous.

\section{NOMENCLATURE}

$a$ Thermal diffusivity, $\mathrm{m}^{2} \cdot \mathrm{s}^{-1}$

$C_{F} \quad$ Inertial coefficient

$C_{P} \quad$ Specific heat at constant pressure, $\mathrm{J} \mathrm{kg}^{-1} \cdot \mathrm{K}^{-1}$

$D$ Hydraulic diameter, $d=2\left(R_{O}-R_{i}\right)$

$D a$ Darcy number, $D a=K / d^{2}$

$E$ Ratio of mean Nusselt number to the product ( $f R e$ ), $E=\left(N u_{b} / f R e\right)$

$f \quad$ FRICTION factor, Eq. (13)

$(f R e)_{0}$ Value of $(f R e)$ in the absence of buoyancy

$g$ Gravitational acceleration

Gr Grashof number, $G r=g \beta \bar{q} d^{4} /\left(v^{2} k_{f}\right)$

$h \quad$ Radial dimension of the each porous block, $m$

Manuscript received April 10, 2014; revised September 15, 2014. This work was supported in part by the Ministry of Higher Education and Research, General Department of Research and Technological Development and the University of Science and Technology Houari Boumediène in Algeria.

Y. Ould-Amer is with the USTHB - Faculty of Mechanical and Process Engineering (FGMGP), Laboratory of Multiphase Transport and Porous Media (LTPMP), Département Energétique, B.P. 32 El-Alia Bab Ezzouar 16111 Algiers, Algeria (e-mail: youldamer@usthb.dz).
$H$ dimensionless radial dimension of each porous block,

$$
H=h / d
$$

$K \quad$ Permeability of the porous blocks, $\mathrm{m}^{2}$

$k_{f}$ Thermal conductivity of the fluid, W. $\mathrm{m}^{-1} \cdot \mathrm{K}^{-1}$

$k_{P} \quad$ Effective thermal conductivity of each porous block

$\mathrm{Nu}$ Local Nusselt number, Eq. (11)

$N u_{b}$ Average Nusselt number, Eq. (12)

$\overline{\mathrm{Nu}}_{0}$ Average Nusselt number in the absence of buoyancy

$P$ Dimensionless pressure, $P=p^{*} /\left(\rho(v / d)^{2}\right)$

$p$ Pressure, $\mathrm{Pa}$

$p^{*} \quad$ Modified pressure, $p^{*}=p-\rho_{w} g r \cos \varphi$

$\operatorname{Pr}$ Prandtl number, $\operatorname{Pr}=(v / a)_{\mathrm{f}}$

$\bar{q} \quad$ Average rate of heat transfer per unit area, W.m $\mathrm{m}^{-2}$

Re Reynolds number, Eq. (15)

$R_{i} \quad$ Radius of inner cylinder, $m$

$R_{o} \quad$ Radius of outer cylinder, $m$

$R R$ Radius ratio, $R R=R_{o} / R_{i}$

$R_{v} \quad$ Viscosity ratio, $R_{v}=\mu_{\mathrm{e}} / \mu_{\mathrm{f}}$

$R_{C}$ Thermal conductivity ratio, $R_{C}=k / k_{f}$

$r \quad$ Radial coordinate, $\mathrm{m}$

$T$ Temperature; ${ }^{\circ} \mathrm{C}$

$T_{b} \quad$ Bulk temperature, ${ }^{\circ} \mathrm{C}$

$T_{w} \quad$ Wall temperature of inner cylinder, ${ }^{\circ} \mathrm{C}$

$U$ Dimensionless velocity in $\varphi$ coordinate, $U=u d / v$

$u \quad$ Velocity component in $\varphi$ coordinate, $\mathrm{m} . \mathrm{s}^{-1}$

$V$ Dimensionless velocity in $\mathrm{r}$ coordinate, $V=v d / v$

$v \quad$ Velocity component in $\mathrm{r}$ coordinate, $\mathrm{m} . \mathrm{s}^{-1}$

$W$ Dimensionless velocity in $\mathrm{z}$ direction,

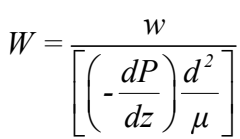

$w \quad$ Velocity in $\mathrm{z}$ direction, $\mathrm{m} . \mathrm{s}^{-1}$

$\bar{W} \quad$ Mean value of $W$

\section{INTRODUCTION}

Heat transfer in annular passages has many applications in the areas of refrigeration, cooling of turbine rotors, nuclear energy production, thermal storage systems, food industries, electrical transport and chemical process. Double pipe heat exchangers in chemical process, gas - cooled electrical cables, double pipe heat exchangers and the cooling of nuclear fuel rods represent industrial examples in which annular flow heat transfer is encountered. In these situations, the forced convection in the duct flow is often significantly influenced by body forces, which tend to produce secondary 
flows in the duct cross section. The main focus of these systems is to enhance the overall heat transfer coefficient.

Laminar mixed convection between concentric horizontal cylinders is presented in [1]-[4]. Niekele and Patankar [4] have examined numerically the effect of buoyancy forces on heat transfer in an annulus. Results are presented for a range of the values of the Gashoff number, the Prandtl number, and the radius ratio of the annulus. Habib and Negm [5] studied numerically the laminar mixed convection in the fully region of horizontal concentric annuli for the case of the non uniform circumferential heating. The problem of mixed convection in a horizontal annulus with isothermal walls, the inner heated and the outer cooled, was studied numerically by Muralidhar [6]. His numerical results indicate that buoyancy increases the rate at which boundary layers grow and it determines the heat transfer rate once the annular gap is filled by the boundary layer on each wall. Vanover and Kulacki [7] conducted experiments in a porous annulus with the inner cylinder heated by constant heat flux and the outer cylinder isothermally cooled. The medium consisted of 1- and 3-mm glass beads saturated with water. They found that when the Rayleigh number is large, the values of the Nusselt number for mixed convection may be lower than the free convection values. They attributed this to restructuring of the flow as forced convection begins to play a dominant role. Laminar mixed convection in the thermal entry region of concentric horizontal annulus of radius 2 has been experimentally studied by Mohammed et al. [8]. The experimental setup consists of a stainless annulus with inner tube subjected to a constant wall heat flux boundary condition and an adiabatic outer annulus. Their experimental results show that the free convection tends to decrease the heat transfer at low Reynolds number while to increase the heat transfer for high Reynolds number.

In the last decades, the use of porous material to improve the heat transfer is of topical interest. Field applications of heat transfer in porous media can be found in [9]-[13]. Ould-Amer [14]-[16] carried out numerical analysis to investigate the performance of an innovative thermal system to improve the heat transfer in horizontal annulus. With attached four porous blocks on the inner cylinder, steady laminar mixed convection is examined for the fully developed region of horizontal concentric annuli. Their results show the significant improve in heat transfer with highly conductive porous medium; however, the friction factor is increased compared with situations without porous blocks. Venugopal et al. [17] studied experimentally the mixed convection in vertical duct filled with metallic porous structure. The main focus of their work is to examine the potential of porous insert for augmenting heat transfer from the heated wall of vertical duct under forced flow conditions. The objective of this work is to analyze the laminar mixed convection in horizontal concentric annuli with the presence of porous matrix. Four porous blocks are fixed on the inner cylinder. The analysis is performed for laminar flow and for thermally and hydrodynamically developed conditions. This study is an extension of previous papers of Ould-Amer [14]-[16].

\section{ANALYSIS}

The physical problem considered in the present paper is shown in Fig. 1. Four porous blocks are fixed on outside of the inner cylinder. The porous blocks are considered homogeneous, isotropic and saturated by an incompressible fluid. The outer cylinder is insulated while the inner cylinder has circumferentially uniform surface temperature and axially uniform heat transfer rate. In the fully developed region of the flow, the velocity components become independent of the axial distance $z$. The density of fluid is considered constant except in the buoyancy term (Boussinesq approximation). A local thermal equilibrium takes place between the fluid and the porous medium. Because of the symmetry about the vertical center line shown in Fig. 1, the analysis is confined to a right half of the annulus.

The continuity, momentum and energy equations that govern the physical situation can be written in dimensionless form as follows:

$$
\begin{aligned}
& \frac{\partial U}{\partial \varphi}+\frac{\partial}{\partial \eta}(\eta V)=0 \\
& \frac{1}{\varepsilon^{2}}\left[V \frac{\partial V}{\partial \eta}+\frac{U}{\eta} \frac{\partial V}{\partial \varphi}-\frac{U^{2}}{\eta}\right] \\
& =-\frac{\partial P}{\partial \eta}-G r \theta \cos \varphi+R_{V}\left[\frac{1}{\eta} \frac{\partial}{\partial \eta}\left(\eta \frac{\partial V}{\partial \eta}\right)+\frac{1}{\eta^{2}} \frac{\partial^{2} V}{\partial \varphi^{2}}\right. \\
& \left.-\frac{V}{\eta^{2}}-\frac{2}{\eta^{2}} \frac{\partial U}{\partial \varphi}\right]-\lambda\left[\frac{V}{D a}+\frac{C_{F}}{\sqrt{D a}}|\vec{V}| V\right] \\
& \frac{1}{\varepsilon^{2}}\left[V \frac{\partial U}{\partial \eta}+\frac{U}{\eta} \frac{\partial U}{\partial \varphi}+\frac{U V}{\eta}\right] \\
& =-\frac{1}{\eta} \frac{\partial P}{\partial \varphi}+G r \theta \sin \varphi+ \\
& R_{V}\left[\frac{1}{\eta} \frac{\partial}{\partial \eta}\left(\eta \frac{\partial U}{\partial \eta}\right)+\frac{1}{\eta^{2}} \frac{\partial^{2} U}{\partial \varphi^{2}}\right. \\
& \left.-\frac{U}{\eta^{2}}+\frac{2}{\eta^{2}} \frac{\partial V}{\partial \varphi}\right]-\lambda\left[\frac{U}{D a}+\frac{\mathrm{C}_{\mathrm{F}}}{\sqrt{D a}}|\vec{V}| U\right] \\
& \frac{1}{\varepsilon^{2}}\left[V \frac{\partial W}{\partial \eta}+\frac{U}{\eta} \frac{\partial W}{\partial \varphi}\right] \\
& =1+R_{V}\left[\frac{1}{\eta} \frac{\partial}{\partial \eta}\left(\eta \frac{\partial W}{\partial \eta}\right)+\frac{1}{\eta^{2}} \frac{\partial^{2} W}{\partial \varphi^{2}}\right]-\lambda \frac{W}{D a} \\
& {\left[V \frac{\partial \theta}{\partial \eta}+\frac{U}{\eta} \frac{\partial \theta}{\partial \varphi}+\frac{4 \frac{W}{\bar{W}}}{\operatorname{Pr}(1+R R)}\right]} \\
& =\frac{1}{\operatorname{Pr}}\left[\frac{1}{\eta} \frac{\partial}{\partial \eta}\left(R_{C} \eta \frac{\partial \theta}{\partial \eta}\right) \theta+\frac{1}{\eta^{2}} \frac{\partial}{\partial \varphi}\left(R_{C} \frac{\partial \theta}{\partial \eta}\right)\right]
\end{aligned}
$$

With dimensionless boundary conditions:

$$
\eta=\eta_{i} \quad W=U=V=0 \quad \theta=0
$$

$$
\eta=\eta_{o} \quad W=U=V=0 \quad \frac{\partial \theta}{\partial \eta}=0
$$




$$
\varphi=0, \pi \quad U=0 \quad \frac{\partial V}{\partial \varphi}=\frac{\partial W}{\partial \varphi}=\frac{\partial \theta}{\partial \varphi}=0 \text { symmetry line }
$$

For convenience, the pressure is redefined as explained in appendix. In the energy equation, the relation between axial temperature gradient and the average heat flux at the surface of the inner cylinder is given in appendix.

At the interfaces which separate the fully fluid zone and the porous blocks, the continuity of flow, pressure, temperature, stress and also energy are adopted.

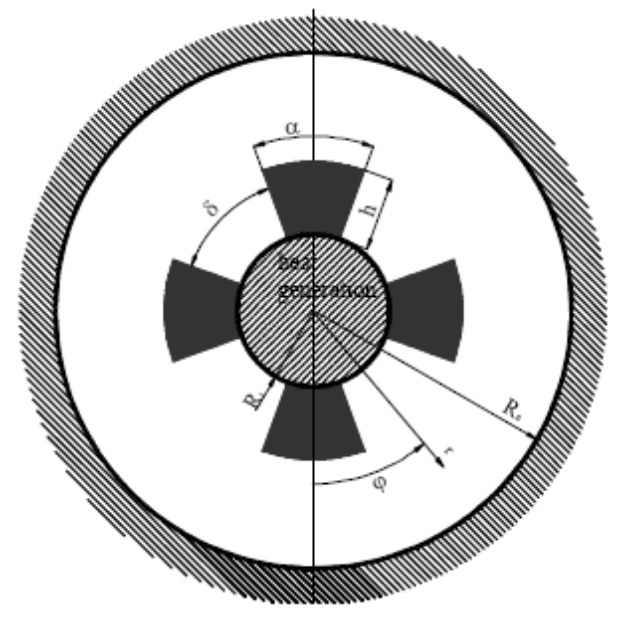

Fig. 1. Physical model.

The porosity is set equal to one in the fully fluid zone and the $\lambda$ parameter and the ratio $R_{C}$ are defined as follows:

$$
\begin{gathered}
\lambda= \begin{cases}0 & \text { in the fully fluid zone } \\
1 & \text { in the porous bloks }\end{cases} \\
R_{C}= \begin{cases}1 & \text { in the fully fluid zone } \\
k_{P} / k_{f} & \text { in the porous bloks }\end{cases}
\end{gathered}
$$

\section{NUMERICAL PROCEDURE}

The set of differential equations governing mixed convection in the horizontal concentric annuli is transformed into a system of algebraic equations with the use of the control volume approach. The SIMPLER algorithm is used for the calculation of the flow field and temperature. The system of algebraic equations is solved iteratively by means of the Thomas algorithm. Under-relaxation factors are introduced to avoid the divergence of the strongly non-linear system. A non uniform staggered grid of $74 \times 64$ nodes was selected on the basis of a grid sensitivity study presented in Table 1. Convergence is controlled in terms of the relative error for the variables $U, V, W, P, \theta$ and the mass residual in each control volume.

The convergence criterion is:

$$
\left|\frac{\Phi_{i j}^{n+1}-\Phi_{i j}^{n}}{\Phi_{i j}^{n}}\right|<10^{-5} \text { and } \mid \text { residual mass }\left.\right|_{\text {in each control volume }}<10^{-5}
$$

With $\Phi$ corresponding to $U, V, W, P$ or $\theta$, and $n$ and $n+1$ indicating two consecutive iterations. The discontinuity between the porous blocks and fully fluid zone is handled with the use of the harmonic mean formulation suggested by Patankar [18]. The present code was validated by comparing the results obtained with our code for the fully fluid case, with those of Nieckele and Patankar [4]. Good agreement between the results is observed in the Table II. The discrepancy for the mean Nusselt number and the friction factor values is less than $1 \%$. The situation of fully fluid case, i.e. without porous blocks, is obtained by setting the Darcy number equal to a large value (typically infinite) and the porosity, $R_{V}$ and $R_{C}$ to one.

TABLE I: GRID SENSITIVITY FOR $G r=10^{6}, D a=10^{-3}, \operatorname{Pr}=1$,
\begin{tabular}{ccc}
$C_{F}=0.011, \varepsilon=0.9, \alpha=60^{\circ}, R_{C}=100, R R=2, H=0.125$ \\
\hline \hline Grid $\varphi \times \eta$ & $N u_{b}$ & $f R e$ \\
\hline $42 \times 32$ & 18.207 & 155.505 \\
\hline $50 \times 42$ & 18.175 & 155.785 \\
\hline $74 \times 64$ & 18.123 & 156.041 \\
\hline $106 \times 92$ & 18.100 & 156.156 \\
\hline
\end{tabular}

TABLE II: COMPARISON OF PRESENT RESUltS WITH THOSE OF NIECKELE AND PATANKAR [4] FOR $\operatorname{Pr}=0.7, R R=2$

\begin{tabular}{ccccc}
\hline \hline \multirow{2}{*}{$G r$} & \multicolumn{2}{c}{ Present code } & \multicolumn{2}{c}{$[4]$} \\
\cline { 2 - 4 } & $\frac{f R e}{(f R e)_{0}}$ & $\frac{N u_{b}}{N u_{0}}$ & $\frac{f R e}{(f R e)_{0}}$ & \\
\hline $10^{3}$ & 1.0000 & 1.0000 & 1.0000 & $\overline{N u_{b}}$ \\
\hline $10^{4}$ & 1.0002 & 1.0027 & 1.0000 & 1.0000 \\
\hline $10^{5}$ & 1.0115 & 1.1156 & 1.0083 & 1.0000 \\
\hline $10^{6}$ & 1.0793 & 1.4650 & 1.0833 & 1.4500 \\
\hline $10^{7}$ & 1.2692 & 1.7859 & 1.2667 & 1.8000 \\
\hline \hline
\end{tabular}

\section{RESUlTS AND DisCUSSION}

\section{A Streamlines and Isotherms}

The fixed input parameters that were used in this work were $\varepsilon=0.9, C_{F}=0.011, \quad R_{V}=1, R R=2, H=0.125$, $\alpha=60^{\circ}, \delta=30^{\circ}$ and $R_{C}=100$ (in the porous blocks). Three values of the Prandtl number were used $P r=1, P r=5$ and $P r=10$ (water). The Grashof number was varied from 10 to $10^{7}$. The numerical solutions were obtained for two values of the Darcy number $D a=10^{-3}$ and $D a=10^{-4}$. In this section, the flow structure and the heat transfer will be analyzed and discussed. The results include some local details of the flow and temperature fields and the overall heat transfer coefficient and friction factor.

The secondary flow pattern and isotherms are displayed in Fig. 2-Fig. 8. Because of the symmetry about the vertical diameter, the isotherms are plotted in the left half and the streamlines in the right half. The value of $\psi_{\text {max }}$ listed for each figure is a measure of the strength of the secondary flow; $\psi_{\max }$ is the maximum value of the dimensionless stream function. For pure forced convection, the secondary flow forms a symmetrical eddy rotating in the clockwise direction, for instance Fig. 2-Fig. 3. The isotherms are nearly circular with a deformation between two consecutive blocks. After a certain threshold value of Gr, depending on $D a$ and $P r$, two or three eddy is formed (Fig. 4-Fig. 8). The two small eddies above and below the main eddy are anti clockwise. As the Grashof number increases, the secondary motion becomes stronger as evidenced by the higher values of $\psi_{\max }$. At 
higher values of $D r$, the isotherm pattern shows the thermal boundary layer near the porous blocks and between them close to heated inner duct. In the region away from and under the inner cylinder, the isotherms tend to become horizontal. The presence of the porous blocks causes the distortion of the isotherms between two consecutive porous blocks, in this region the heat transfer decreases. At lower Prandtl number $(P r=1)$, the second eddy takes place at $G r \geq 10^{6}$, whereas at higher values of $\operatorname{Pr}(\operatorname{Pr}=5$ or 10), this phenomena occurred at lower values of $G r\left(G r \geq 10^{5}\right)$. The distortion of the isotherm is very pronounced for higher values of Prandtl number, Whereas the strength of the secondary flow is significantly larger for $P r=1$ than for $P r=5$ or 10 . One consequence is that, for the same Grashof number, the eddy makes its appearance for $P r=5$ or 10 for instance Fig. 3-Fig. 4.

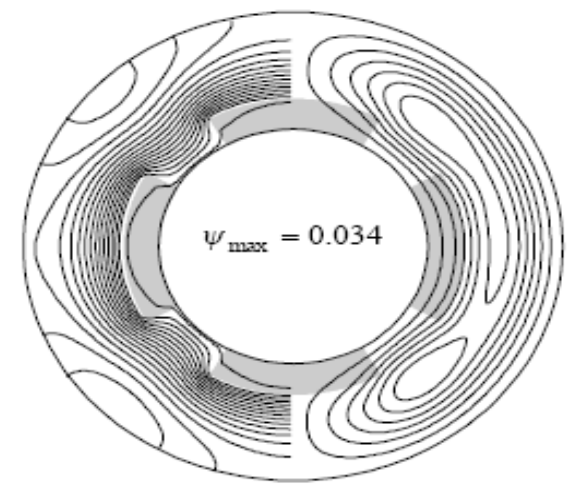

Fig. 2. Isotherms and streamlines for $G r=10^{3}, \operatorname{Pr}=5, D a=10^{-3}$.

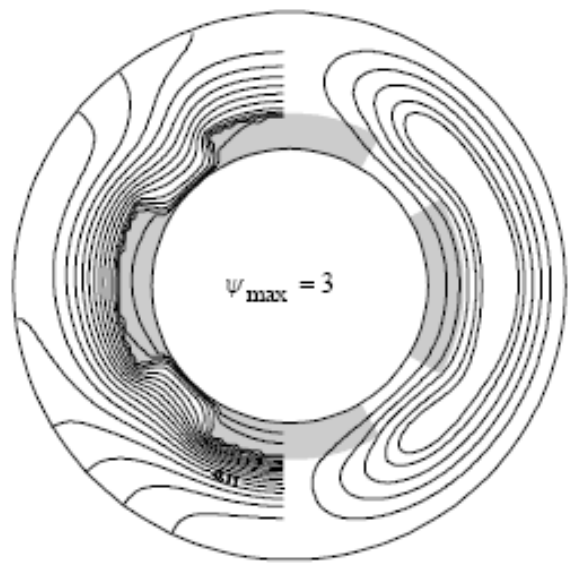

Fig. 3. Isotherms and streamlines for $G r=10^{5}, \operatorname{Pr}=1, D a=10^{-3}$.

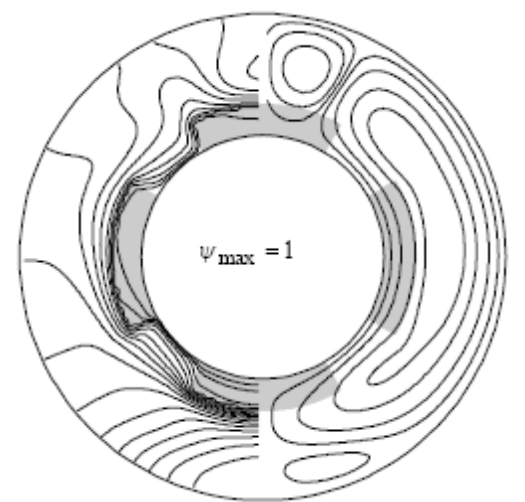

Fig. 4. Isotherms and streamlines for $G r=10^{5}, P r=10, D a=10^{-3}$.

For the design purposes, the overall heat transfer in the device is of primary interest. The overall heat transfer results are presented in the form of the average Nusselt number $N u_{b}$. The average Nusselt number is evaluated as (see appendix):

$$
N u_{b}=-\frac{1}{\theta_{\mathrm{b}}}
$$

where $\theta_{\mathrm{b}}$ is the dimensionless bulk temperature of the fluid, defined in appendix.

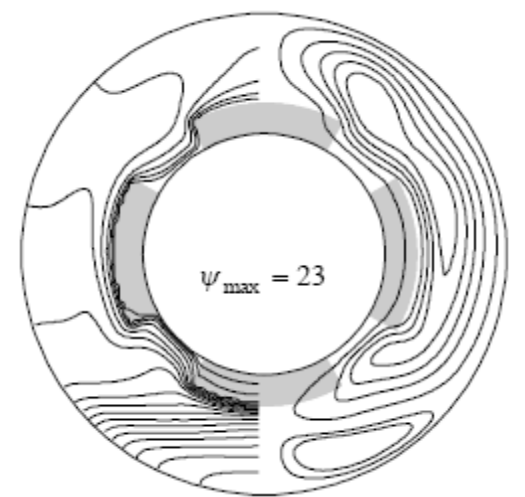

Fig. 5. Isotherms and streamlines for $G r=10^{7}, \operatorname{Pr}=1, D a=10^{-4}$.

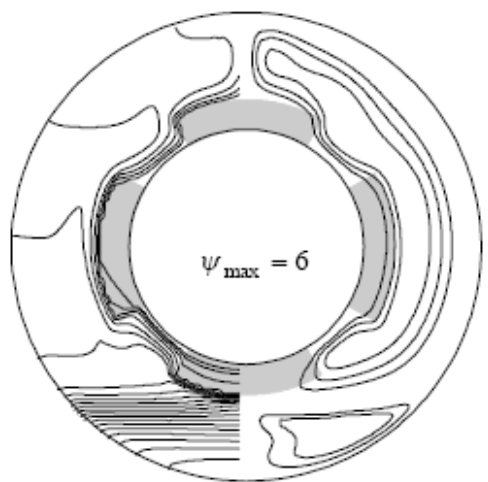

Fig. 6. Isotherms and streamlines for $G r=10^{7}, \operatorname{Pr}=10, D a=10^{-4}$.

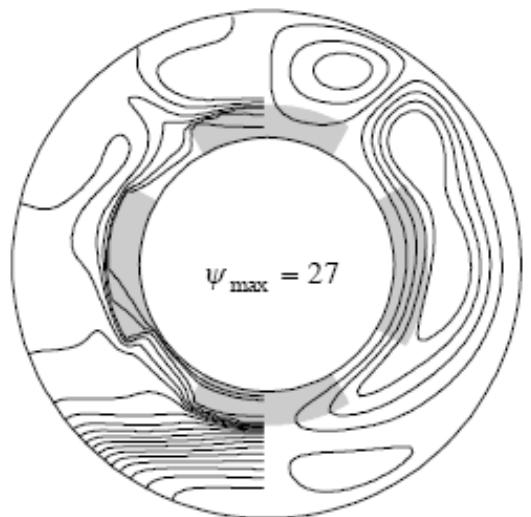

Fig. 7. Isotherms and streamlines for $G r=10^{7}, \operatorname{Pr}=10, D a=10^{-3}$.

\section{A. Overall Heat Transfer Coefficient}

The variation of $N u_{b}$ with $\mathrm{Gr}$ is shown in Figures 9 and 10 for various values of $\operatorname{Pr}$. The effect of porous blocks insertion is to increase $N u_{b}$; and this becomes more noticeable at higher values of $G r$. For pure forced convection, $N u_{b}$ is independent of Prandtl number. The heat transfer is improved, more particularly with the higher values of Pr. Indeed, at $G r=10^{7}$ and $D a=10^{-3}, N u_{b}$ goes approximately from 17 for $\operatorname{Pr}=1$ to 56 for $\operatorname{Pr}=10$ and from 12 for $\operatorname{Pr}=1$ to 26 
for $\operatorname{Pr}=10$ at $D a=10^{-4}$. This enhancement is attributable to the combined effect of highly conductive porous blocks and buoyancy. Indeed, the porous blocks acting as extended surfaces for heat transfer. Further, the higher the Prandtl number, the smaller is the value of $G r$ at which the buoyancy forces begin to affect the value of the average Nusselt number.

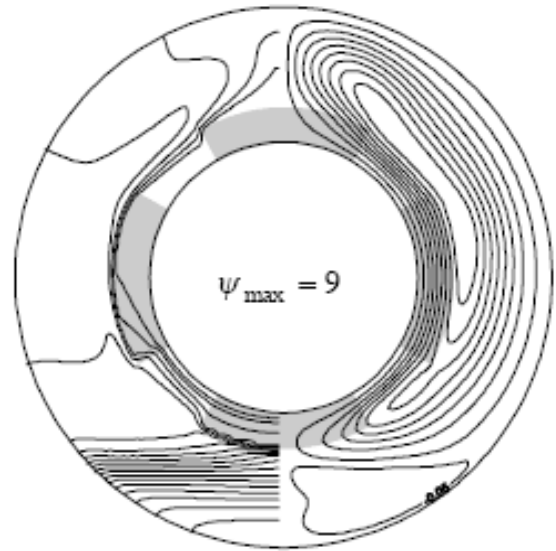

Fig. 8. Isotherms and streamlines for $G r=10^{7}, \operatorname{Pr}=10, D a=10^{-3}$.

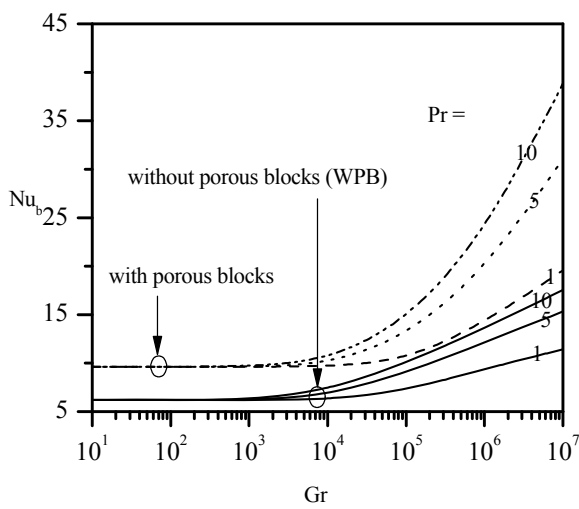

Fig. 9. Overall Nusselt number for $D a=10^{-4}$.

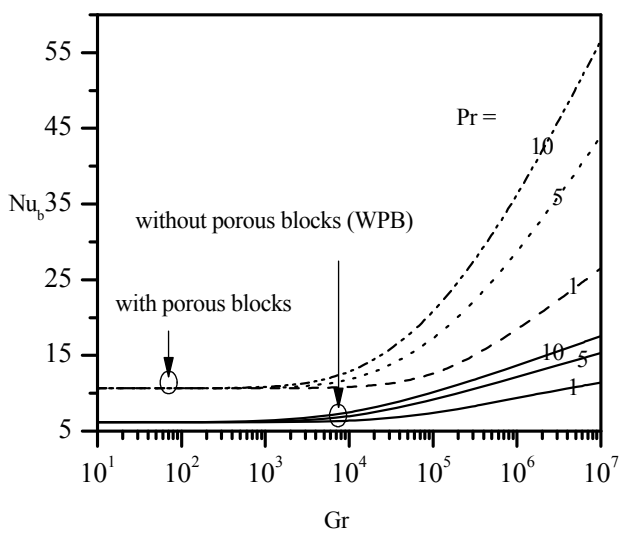

Fig. 10. Overall Nusselt number for $D a=10^{-3}$.

\section{B. Friction Factor}

The increased heat transfer in mixed convection and with presence of porous media does not come without a penalty. The pressure gradient required for a given mass flow rate through the duct also increases in magnitude. The axial pressure drop for the flow can be expressed in terms of the friction factor $f$, where $f$ is given by the standard definition:

$$
f=\frac{-\left(\frac{\partial p}{\partial z}\right) d}{\frac{1}{2} \rho \bar{w}^{2}}
$$

If previous equation is rewritten in terms of the dimensionless variables, there results:

$$
f R e=\frac{2}{\bar{W}}
$$

With

$$
R e=\frac{\rho \bar{w} d}{\mu}
$$

The dimensionless mean value of $W$ is given in appendix. In the absence of the secondary flow, the product $f R e$ is constant, which depends only on the Darcy number.

Fig. 11-Fig. 12 show the product $f$ Re plotted as a function of $\mathrm{Gr}$ for different values of $\mathrm{Pr}$. The influence of buoyancy becomes noticeable only after a certain threshold value of $G r$ is exceeded. Since Stronger secondary flows are associated with increasing values of $G r$. The increase in friction factor due to porous blocks is seen to be significantly large with lower values of $\mathrm{Pr}$. The flow resistance increases with the $P r$ decrease. Indeed, the high Prandtl numbers are associated with relatively weaker secondary flows and lead to a smaller value of $f R e$.

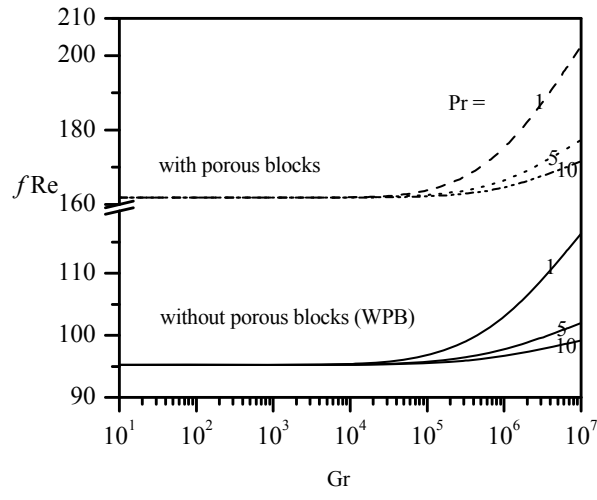

Fig. 11. Friction factor for $D a=10^{-4}$.

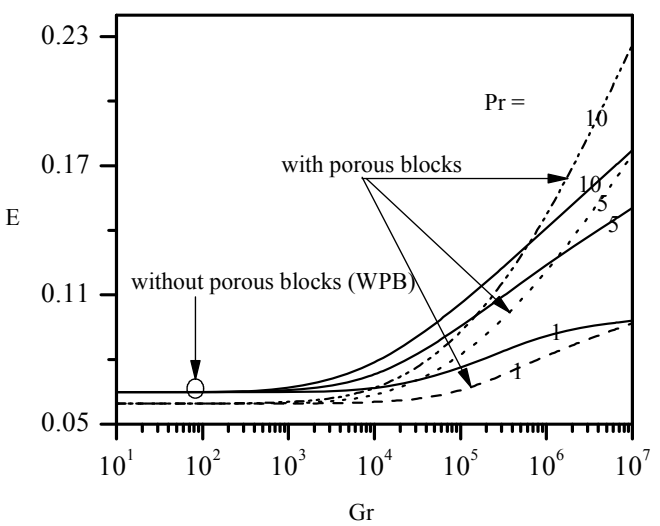

Fig. 13. Efficiency for $D a=10^{-4}$. 


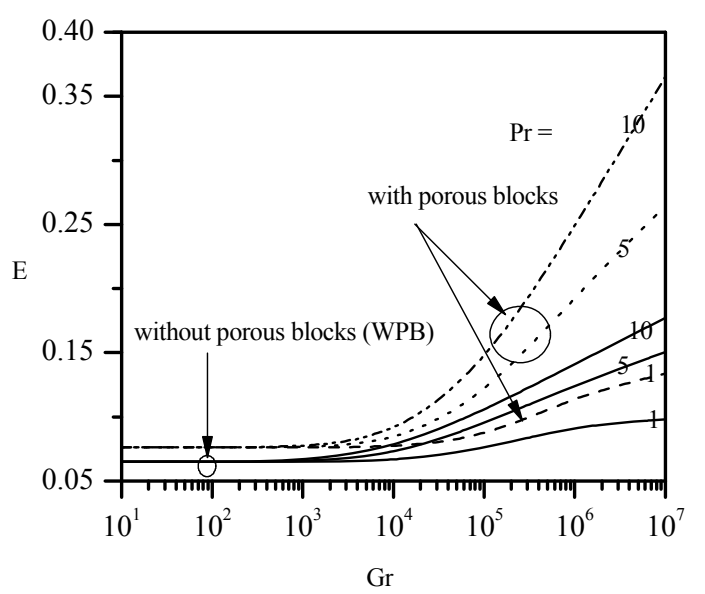

Fig. 14. Efficiency for $D a=10^{-3}$.

\section{Efficiency}

From previous discussion of the overall heat transfer coefficient and the friction factor, it appears that $\mathrm{Nu}_{\mathrm{b}}$ increases with higher values of $\mathrm{Pr}$; and on the other hand $f$ Re increases with the presence of the porous matrix. For this reason a new parameter must be taken into consideration in design calculations. It corresponds to ratio of the mean Nusselt number to the quantity $f$ Re defined as: $E=\left(N u_{b} / f R e\right)$. Fig. 13-Fig. 14 show the ratio E plotted as a function of $\mathrm{Gr}$ for different values of $\mathrm{Pr}$. The plot for the situation without porous blocks is shown by solid line and is considered as reference. It can be seen that the ratio $\mathrm{E}$ is significantly influenced by the presence of porous blocks.

At $D a=10^{-3}$, E is improved for all value of $\operatorname{Pr}$. However, at $D a=10^{-4}$, the improvement occurred only for $\operatorname{Pr}=10$ and 5 and after a certain threshold value of $\mathrm{Gr}$ is exceeded as showed in Fig. 13. Thus, the efficiency is significantly affected by the Darcy number of the porous blocks.

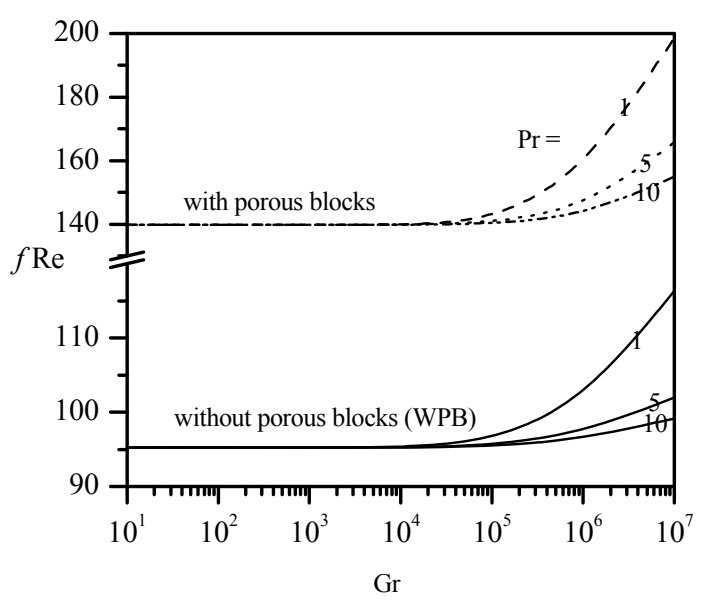

Fig. 12. Friction factor for $D a=10^{-3}$

\section{CONCLUSION}

According to the simulated results, the present research has led to the following conclusions:

- The use of porous blocks increases the overall heat transfer coefficient more particularly with higher values of $\mathrm{Pr}$.
- The friction factor is very affected by the presence of porous structure; it increases with the Darcy number decrease.

The use of porous blocks leads to an improvement of efficiency for all value of Prandtl number at $D a=10^{-3}$, however, at $D a=10^{-4}$ this occurred only for $\operatorname{Pr}=10$ and 5 and after a certain threshold value of $G r$ is exceeded.

\section{APPENDIX}

The pressure gradient and body force terms in the momentum equation for the radial direction are:

$$
-\frac{\partial p}{\partial r}+\rho g \cos \varphi
$$

The density $\rho$ is given by:

$$
\rho=\rho_{\mathrm{w}}[1-\beta(T-T w)]
$$

With a modified pressure $p^{*}$ defined as:

$$
p^{*}=p-\rho_{\mathrm{w}} g \mathrm{r} \cos \varphi
$$

It is possible to write Eq. (14) as:

$$
-\frac{\partial p}{\partial \mathrm{r}}+\rho g \cos \varphi=-\frac{\partial p^{*}}{\partial r}-\rho_{\mathrm{w}} g \beta\left(T-T_{w}\right) \cos \varphi
$$

The corresponding terms in the $\varphi$ direction momentum equation can be similarly written as:

$$
-\frac{1}{\mathrm{r}} \frac{\partial p}{\partial \varphi}-\rho \mathrm{g} \sin \varphi=-\frac{1}{r} \frac{\partial p^{*}}{\partial \varphi}+\rho_{\mathrm{w}} g \beta\left(T-T_{w}\right) \sin \varphi
$$

The dimensionless bulk temperature $\theta_{b}$ is calculated from:

$$
\theta_{b}=\frac{\iint \theta W \eta d \eta d j}{\iint W \eta d \eta d j}
$$

The dimensionless mean value of $\mathrm{W}$ is calculated from:

$$
\bar{W}=\frac{\iint W \eta d \eta d j}{\iint \eta d \eta d j}
$$

In the thermally developed region, the temperature $T_{w}$ and any local temperature $T$ of the fluid in the annulus vary linearly with $\mathrm{z}$ direction at the same constant rate determined by $Q^{\prime}$, the rate of heat flow per unit axial length.

The axial rate of rise of the fluid temperature $T$ can be related to the heat flow rate $Q^{\prime}$ by means of the overall heat balance.

$$
\frac{\partial T}{\partial z}=\frac{\partial T_{w}}{\partial z}=\frac{Q^{\prime}}{\rho C_{P} \bar{w} \pi\left(R_{O}^{2}-R_{i}^{2}\right)}
$$

If $\bar{q}$ represents the average heat flux at the surface of the inner cylinder, then $\bar{q}$ and $Q^{\prime}$ are related by: 


$$
Q^{\prime}=2 \pi R_{i} \bar{q}
$$

Thus:

$$
\frac{\partial T}{\partial z}=\frac{\partial T_{w}}{\partial z}=\frac{2 \bar{q} R_{i}}{\rho C_{P} \bar{w}\left(R_{O}^{2}-R_{i}^{2}\right)}
$$

The mean Nusselt number is defined as:

$$
\bar{h}\left(T_{w}-T_{b}\right)=\bar{q}
$$

Equation (24) is multiplied by $\left(\frac{d}{k_{f}}\right) \times\left(\frac{1}{T_{w}-T_{b}}\right)$, then we obtain:

$$
\frac{\bar{h} d}{k_{f}}=N u_{b}=\left(\frac{\bar{q} d}{k_{f}}\right) \times\left(\frac{1}{T_{w}-T_{b}}\right)
$$

Thus:

$$
N u_{b}=-\frac{1}{\theta_{b}}
$$

\section{ACKNOWLEDGMENT}

We would like to thank the Ministry of Higher Education and Research, General Department of Research and Technological Development and the University of Science and Technology Houari Boumediène.

\section{REFERENCES}

[1] J. Huetz and J. P. Petit, "Natural and mixed convection in concentric annular spaces-experimental and theoretical results for liquid metals," in Proc. the Fifth International Heat Transfer Conference, Tokyo, 1974, pp. 169-172.

[2] T. H. Nguyen, P. Vasseur, L. Robillard, and B. C. Shekar, "Combined free and forced convection of water between horizontal concentric cylinders," ASME J. Heat Transfer, vol. 105, pp. 498-504, 1983.

[3] H. Naozo, "Combined free and forced convection heat transfer for fully developed laminar flow in concentric annuli," Num. Analysis trans. JSME, vol. 45, pp. 227-239, 1979.

[4] A. O. Nieckele and S. V. Patankar, "Laminar mixed convection in a concentric annulus with horizontal axis," ASME J. Heat Transfer, vol. 107, pp. 902-909, 1985.

[5] M. A. Habib and A. A. A. Negm, "Laminar mixed convection in horizontal concentric annuli with nonuniform circumferential heating," Heat and Mass Transfer, vol. 37, pp. 427-435, 2001.

[6] K. Muralidhar, "Mixed convection flow in a saturated porous annulus," I. J. Heat Mass Transfer, vol. 32, pp. 881-888, 1989.

[7] D. E. Vanover and F. A. Kulacki, "Experimental study of mixed convection in a horizontal porous annulus," ASME HTD, vol. 84, pp. $61-66,1987$.

[8] H. A. Mohammed, A. Compo, and R. Saidur, "Experimental study of forced and free convective heat transfer in the thermal entry region of horizontal concentric annuli," I. Com. in Heat and Mass Transfer, vol. 37, pp. 739-747, 2010.

[9] D. Nield and A. Bejan, Convection in Porous Media, $3^{\text {rd }}$ edition, Springer, New York, 2006.

[10] K. Vafai, Handbook of Porous Media, $2^{\text {nd }}$ edition, Taylor \& Francis, New York, 2005.

[11] D. B. Ingham and I. Pop, Transport Phenomena in Porous Media, Elsevier, Oxford, 2005.

[12] P. Vadasz, "Emerging topics in heat and mass transfer in porous media," Springer, New York, 2008

[13] M. Kaviany, Principles of Heat Transfer in Porous Media, Springer, New York, 1994.

[14] Y. O. Amer, "Laminar mixed convection in horizontal concentric annuli with four porous blocks attached on the outside of the inner cylinder," in Proc. the 2010 10th Biennial Conference on Engineering Systems Design and Analysis (ESDA2010), pp. 433-442, 2010.

[15] Y. O. Amer, "Optimal heat transfer in horizontal concentric annuli with the presence of porous structure," in Proc. International Conference on Mechanical Engineering and Technology, vol. 77, pp. 486-494, 2010.

[16] Y. O, Amer and B. Madani, "éCoulement secondaire et principal dans un tube annulaire en présence d'un milieu poreux," Congrès national de mécanique des fluides, Alger 25-26 septembre 2012, USTHB, Bab Ezzouar, Algérie.

[17] G. Venugopal, C. Balaji, and S. P. Venkateshan, "Experimental study of mixed convection heat transfer in a vertical duct filled with metallic porous structures," I. J. of Thermal Sciences, vol. 49, pp. 340-348, 2010.

[18] S. V. Patankar, Numerical Heat Transfer and Fluid Flow, McGraw-Hill, New York, 1980.

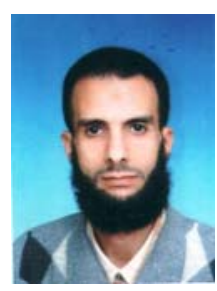

Y. Ould-Amer was born in Algiers on May 12th 1968. After growing up in Algiers he attended the primary and the secondary school in Algiers before going to the University of Science and Technology Houari Boumediene in 1987 in the Department of Mechanical Engineering. He graduated in June 1993 with a bachelor of thermo-energy in mechanical engineering.

He received his master of industrial thermal systems in mechanical engineering from Houari Boumediene University in 1996. $\mathrm{He}$ then pursued and completed his $\mathrm{PhD}$ of mechanical engineering at Houari Boumediene University in October of 2004.

For his master, Yacine worked on the cooling enhancement of electronic component by the use of porous materials. This research is published in the International Journal of Heat and Fluid Flow. For his $\mathrm{PhD}$, he presented a research on the dual completion technology in the petroleum field. As a result, two research papers are produced and published in the Journal of Porous Media and the Journal of Petroleum Science and Engineering.

Yacine has worked in the university Houari Boumediene as an assistant from 1994 to 1995, as an assistant professor from 1996 to 2003, as an assistant lecturer from 2004 to 2012 and from 2013 until today he occupies the post of professor.

Prof. Ould-Amer has a research working in porous media, heat transfer and petroleum field. $\mathrm{He}$ has participated on several international conferences in the world as JITH 2007, CHT'2008, ICAPM2009, ASME 2010 and ICMET 2013. 